\title{
An Unconditionally Stable Voltage Regulator
}

\author{
Paulo Crepaldi ${ }^{\# 1}$, Tales Pimenta ${ }^{\# 2}$, Robson Moreno ${ }^{\# 3}$, Edgard Charry Rodriguez ${ }^{* 4}$ \\ ${ }^{\text {\#} U n i v e r s i d a d e ~ F e d e r a l ~ d e ~ I t a j u b a ~}$ \\ Av. BPS, 1303 Itajuba-MG Brazil \\ ${ }^{1,2,3}$ crepaldi@unifei.edu.br \\ *Universidade de São Paulo \\ Av. Prof. Luciano Gualberto, 158 São Paulo-SP-Brasil \\ ${ }^{4}$ charry@terra.com.br
}

\begin{abstract}
This paper describes a CMOS implementation of a Linear Voltage Regulator (LVR) used to power implanted systems. The topology is based on a classical structure of a Low Dropout Regulator (LDO) and receives his activation energy from a RF link characterizing a passive RFID tag. The LVR was designed to achieve important features like low power consumption, and a small silicon area without the need for any external discrete components. The project was implemented in a $0.35 \mu \mathrm{m} C M O S$ process and a prototype was tested to validate the overall performance. The LVR output is regulated at $1 \mathrm{~V}$ and supplies a maximum load current of $0.5 \mathrm{~mA} @ 37^{\circ} \mathrm{C}$. The load regulation is $13 \mathrm{mV} / \mathrm{mA}$ and the line regulation is $39 \mathrm{mV} / \mathrm{V}$. The LVR total power consumption is $1.2 \mathrm{~mW}$.
\end{abstract}

Keywords - Linear Voltage Regulator, Implanted Device, RFID.

\section{INTRODUCTION}

Patient monitoring systems can be found in a wide range of application on hospitals like in the Intensive Care Unit. When the equipments are connected to a communication network they form a telemedicine system by which the patients can be monitored remotely, even over the Internet [1].

Therefore, there is a demand for sensors and signal conditioners that can be placed directly on the patient or, even, implanted. The implanted device forms a biological data acquisition system (biotelemetry) of physiological signals. The implanted devices must meet important constrains such as reduced size, low power consumption and the possibility of being powered by an RF link, acting as passive RFID tag [2].

The impact of temperature variations in implantable devices is minimized once the body temperature is kept stable at approximately $37^{\circ} \mathrm{C}$. The classic topologies designed to obtain power supply voltage stability are the voltage regulators that can be classified as linear or switched regulators. Switched regulators present a complex topology, mainly in its control systems, frequently requiring larger power consumption and larger silicon area. Additionally it provides more noise at the regulated output due to its switched operation [3]. The low-dropout (LDO) voltage regulators is one of the most popular power converters used in power management [4] and is more suitable for an implanted system. The pass element can be implemented using bipolar or MOS transistors. Since a MOS transistor is controlled by its gate voltage, it offers the advantage of smaller power consumption and consequently higher efficiency for the voltage regulator.
The MOS transistor can be either N or P type. The NMOS transistor requires a gate voltage higher than the source voltage, and therefore it may be necessary a charge pump to increase the voltage level. The proper choice for low voltage systems, such as implantable devices, it is the use of a PMOS LDO [5].

\section{Circuit TOPOlOGY}

Figure 1 illustrates the contribution presented in this work, by the introduction of a source follower stage (transistor $\left.\mathrm{MN}_{\mathrm{FOL}}\right)$ and the replacement of the resistive sampler $\left(\mathrm{R}_{1}\right.$ and $R_{2}$ ). The resistive sampler was replaced by a single MOS transistor along with a grounded MOS resistor (biasing from transistor $\left.\mathrm{MN}_{\mathrm{AUX}}\right)$. In the proposed circuit, the load capacitance $\left(C_{L}\right)$ represents the internal capacitance of the subsystems that are supplied by the regulator.

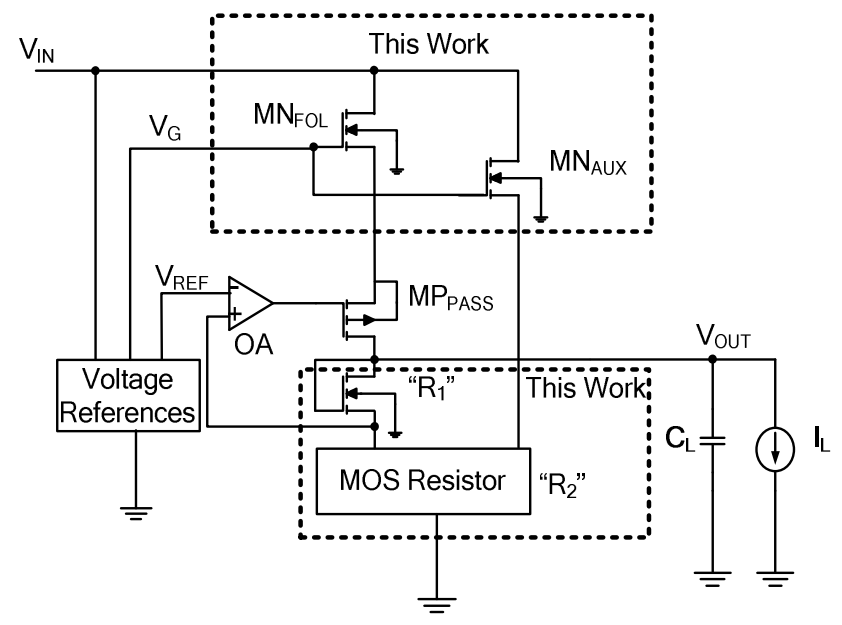

Figure 1 - Simplified diagram of the proposed linear voltage regulator.

The input voltage comes from the RF link and is rectified and filtered. Finally, the current source $\mathrm{I}_{\mathrm{L}}$ represents the overall current consumption of the powered subsystems. The supply voltage goal is $1 \mathrm{~V}$ for a maximum current load of $0.5 \mathrm{~mA}$. Consequently, the total power required by the remaining subsystems is $0.5 \mathrm{~mW}$. The source follower stage (transistor $\mathrm{MN}_{\mathrm{FOL}}$ ) was added in order to provide stability to the LDO system, as it will be shown in item 5 . 


\section{OPERATIONAL AMPLIFIER}

In this design, the OA is an OTA amplifier since its load is purely capacitive, represented by the input gate capacitance of the pass transistor MP $P_{\text {PASS }}$. The OTA circuit is presented in Figure 2 and it is implemented as a self-biased folded cascode [6]. The cascode topology has the advantages of improved power supply rejection ratio (PSRR) and presents a dominant pole that is determined only by the load capacitance. The power consumption of the OTA is kept as low as possible to avoid degrading the efficiency of the LVR. The OTA layout was carefully developed using a centroid configuration to minimize any offset voltage. Table I summarizes the main OTA measured parameters.

TABLE I

OTA MEASURED PARAMETERS

\begin{tabular}{|c|c|}
\hline \multicolumn{2}{|c|}{ Measured values $\boldsymbol{(} \mathbf{T}_{\mathbf{N O M}}$ and $\mathbf{C}_{\mathbf{L}}=\mathbf{5} \mathbf{p F}$} \\
\hline Supply Voltage $[\mathrm{V}]$ & 2.2 \\
\hline Supply Current $[\mu \mathrm{A}]$ & 3.7 \\
\hline Open Loop Gain $[\mathrm{dB}]$ & 75.8 \\
\hline Unit Gain Frequency $\left[\mathrm{MH}_{\mathrm{Z}}\right]$ & 0.16 \\
\hline Phase Margin & $66.5^{0}$ \\
\hline Slew Rate $[\mathrm{V} / \mu \mathrm{S}]$ & $\mathrm{SR}^{+}=\mathrm{SR}^{-}=0.02$ \\
\hline $\mathrm{T}_{\mathrm{SET}} @ 0.1 \%[\mu \mathrm{S}]$ & 5.8 \\
\hline PSRR @ $10 \mathrm{MH}_{\mathrm{Z}}[\mathrm{dB}]$ & -32 \\
\hline Offset Voltage $[\mathrm{mV}]$ & 4.1 \\
\hline Power Dissipation $[\mu \mathrm{W}]$ & 8.2 \\
\hline
\end{tabular}

\section{Voltage REFERENCES CiRCUIT}

The LVR requires two voltages references. The VG reference is necessary to bias the source follower stages represented by $M_{N F O L}$ and $M_{N A U X}$. The $V_{R E F}$ reference is used, in the closed loop system, to obtain the LVR output voltage as a function of the sampler circuit as indicated by equation (1).

$$
V_{\text {OUT }}=\left(1+\frac{R_{1}}{R_{2}}\right) \cdot V_{R E F}
$$

Bandgap references are generally used in LDO designs. There are alternative circuits capable of obtaining low-voltage and high-accuracy, nevertheless those approaches may require components not readily available in CMOS technology (additional fabrications steps), or CMOS transistor on subthreshold operation, or floating gate or even by using trimming. Figure 3 presents the proposed topology that is simple and requires small silicon area, and requires just a few $\mu \mathrm{W}$. Figure 3 presents the proposed topology that is simple and requires small silicon area, and requires just a few $\mu \mathrm{W}$. Since the circuit is intended to be used in an implanted device, the temperature variation is negligible, and therefore it is not taken into account. The core of this reference circuit is the self biased current mirror composed by $\mathrm{MN}_{1}, \mathrm{MP}_{1}, \mathrm{MP}_{2}$ and $\mathrm{Q}_{1}$. The use parasitic PNP bipolar transistor $\mathrm{Q}_{1}$ in the CMOS digital technology is justified since it presents a known $V_{B E}$ voltage and its temperature behavior. To obtain higher voltage
$\mathrm{V}_{\mathrm{G}}$, other currents mirrors and successive cascade of bipolar transistor are used. A $2 \mathrm{~V}$ value is needed to bias the source follower stage $\left(\mathrm{MN}_{\mathrm{FOL}}\right)$ and the auxiliary voltage follower $\mathrm{MN}_{\mathrm{AUX}}$.

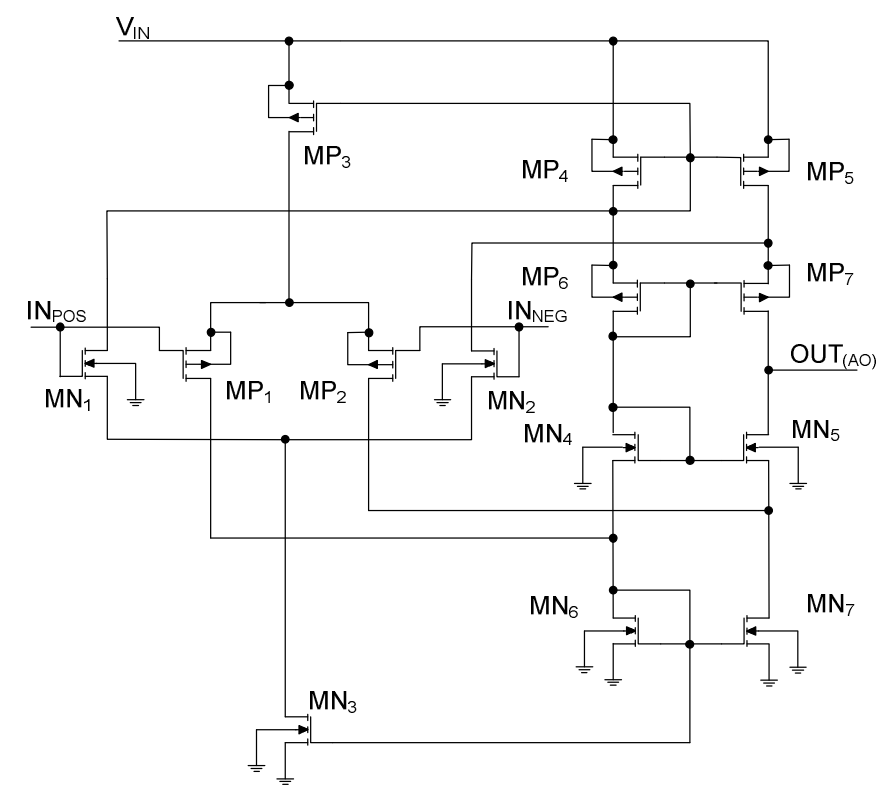

Figure 2 - Operational amplifier (OTA) circuit.

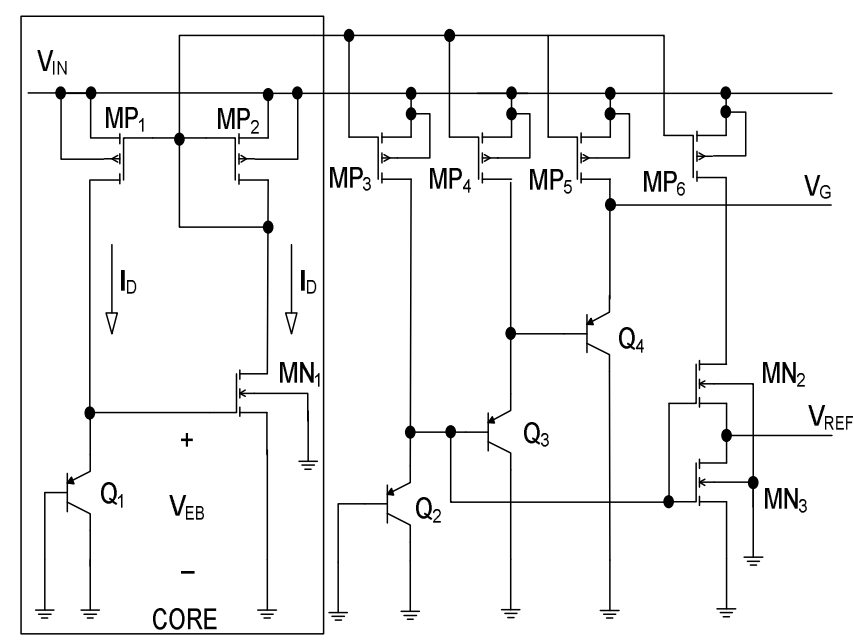

Figure 3 - Voltage reference circuit.

Voltage $\mathrm{V}_{\mathrm{REF}}$ is derived from $\mathrm{V}_{\mathrm{BE}}$ of transistor $\mathrm{Q}_{2}$ and its value is fixed in $200 \mathrm{mV}$. It uses a composite structure of two MOS transistors, $\mathrm{MN}_{2}$ and $\mathrm{MN}_{3}$. The composite MOS transistor improves the PSRR of the voltage reference [7].

The total circuit area is just $0.003 \mathrm{~mm}^{2}$. The self biased current mirror was designed to operate with a $4 \mu \mathrm{A}$ base current, which is the $\mathrm{MN}_{1}$ transistor drain current. By considering the mirrors implemented through transistors $\mathrm{MP}_{3}$, $\mathrm{MP}_{4}, \mathrm{MP}_{5}$ and $\mathrm{MP}_{6}$ (current gain of 1), the total current of the reference generator circuit is $24 \mu \mathrm{A}$. Table II presents a comparison of this work with others presented in the literature. 
TABLE II

REFERENCES CAPARISON

\begin{tabular}{|l|l|l|l|l|}
\hline & $\begin{array}{c}\text { This } \\
\text { Work }\end{array}$ & \multicolumn{1}{|c|}{$[8]$} & \multicolumn{1}{|c|}{$[9]$} & \multicolumn{1}{|c|}{$[10]$} \\
\hline Technology $[\mu \mathrm{m}]$ & 0.35 & 0.18 & 0.6 & 0.35 \\
\hline Supply Voltage $[\mathrm{V}]$ & 2 to 2.4 & 1.1 to 1.8 & 0.98 to 1.5 & 1.5 to 4.3 \\
\hline $\mathrm{V}_{\text {REF }}[\mathrm{V}]$ & 0.2 & 1.012 & 0.603 & 0.67 \\
\hline TC[ppm $\left.{ }^{0} \mathrm{C}\right]$ & N/A & 4 & 15 & 10 \\
\hline Supply Current $[\mu \mathrm{A}]$ & $<25$ & $<14$ & $<18$ & $<0.11$ \\
\hline PSRR@10 $10 \mathrm{MH}_{\mathrm{Z}}[\mathrm{dB}]$ & -38 & -23 & -17 & -40 \\
\hline
\end{tabular}

\section{SAMPLER CIRCUIT}

Figure 4 presents the sampler circuit, where $R_{1}$ is realized as a MOS diode $\left(\mathrm{MN}_{2}\right)$ and $\mathrm{R}_{2}$ is implemented through an interesting topology, a grounded MOS resistor [11].

The relationship $R_{1} / R_{2}$ is optimized by the adjustments of the aspect ratio of transistor $\mathrm{MN}_{2}$. The measured current consumption of the PMOS transistor array is $2.94 \mu \mathrm{A}$ and the current $\mathrm{I}_{R E S}$ is $5.2 \mu \mathrm{A}$. Thus, the equivalent resistor $\mathrm{R}_{2}$ is approximately $38.5 \mathrm{~K} \Omega$ and $\mathrm{R}_{1}$ is approximately $153.8 \mathrm{~K} \Omega$. From expression (1), the output voltage is given as:

$$
V_{\text {OUT }}=\left(1+\frac{153.8 K}{38.5 K}\right) \cdot 200 m V \approx 1 V
$$

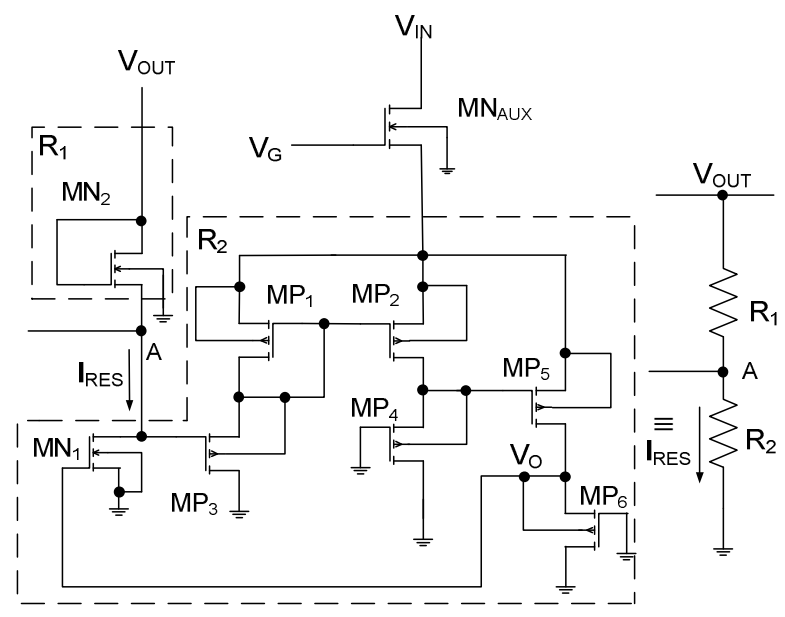

Figure 4 - Sampler circuit

\section{STABILITY ANALYSIS}

The frequency response is degraded by the presence of two poles besides the dominant one that can lead an unstable system condition. It is necessary to add a zero between these two poles to compensate the frequency response. The insertion of this zero is normally done by adding a discrete capacitor $\left(\mathrm{C}_{\mathrm{COMP}}\right)$ in the output node [12]. The solution proposed in this work is the introduction of a source follower $\left(\mathrm{M}_{\mathrm{NFOL}}\right)$ stage in between the input voltage and the LDO block, and the removal of the compensation capacitor $\mathrm{C}_{\mathrm{COMP}}$. This stage maintains the PMOS pass transistor in the triode region (small values for $\mathrm{V}_{\mathrm{DS}}$ ). $\mathrm{R}_{\mathrm{DS}}$ can be expressed as:

$$
R_{D S} \cong \frac{1}{\left(\frac{K P}{2(1+\delta)} \frac{W}{L}\right)\left(V_{G S}-V_{T H}-V_{D S}\right)}
$$

Where $\delta$ is a short channel fitting parameter, $\mathrm{V}_{\mathrm{TH}}$ is the threshold voltage and $\mathrm{W} / \mathrm{L}$ is the geometric aspect ratio. $R_{D S}$ can be designed to be smaller than resistors $R_{1}$ and $R_{2}$ of the sampling circuit. $R_{D S}$ was chosen to be $100 \Omega$ for our LVR. The system poles, under the new approach are:

$$
\begin{gathered}
f_{P 0}=\frac{-1}{2 \pi\left[R_{D S} / /\left(R_{1}+R_{2}\right)\right] \cdot C_{L}} \approx \frac{-1}{2 \pi R_{D S} C_{L}} \\
f_{P 2}=\frac{-1}{2 \pi R_{A O} C_{G P A S S}}
\end{gathered}
$$

Where $\mathrm{R}_{\mathrm{AO}}$ is the output resistance of OTA and $\mathrm{C}_{\mathrm{GPASS}}$ is the gate capacitance of the PMOS pass transistor.

Since the $R_{A O}$ is much larger than $R_{D S}, f_{P 2}$ becomes a dominant pole, and consequently, the closed loop system becomes stable. The derived values for $f_{\mathrm{P} 0}$ and $\mathrm{f}_{\mathrm{P} 2}$ are, respectively, $318 \mathrm{MHZ}$ and $133 \mathrm{HZ}$. Figure 5 presents the frequency response of the proposed LVR.

As can be seen the unity frequency gain is approximately $580 \mathrm{KHz}$ leading and the margin phase $66.5^{\circ}$ leading to a an unconditionally stable system. The source follower stage is a disadvantage for the system since it represents additional power consumption. Nevertheless, the system does not require the external components to become stable, thus representing an important advantage for an implantable system.

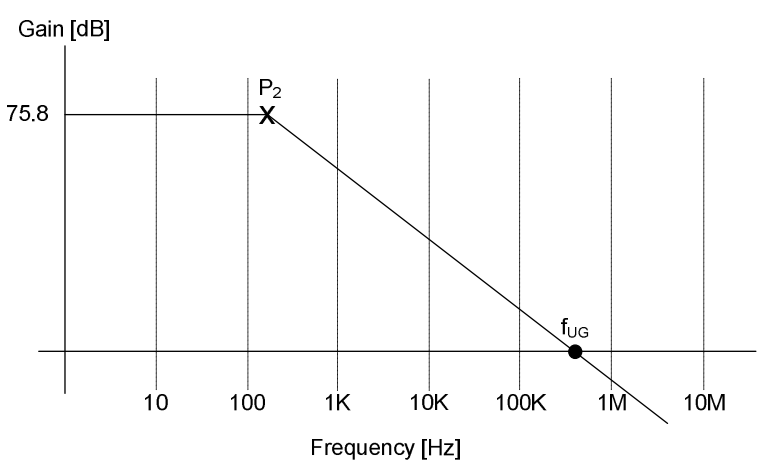

Figure 5 - Frequency response of the proposed LVR.

Figure 6 shows the microphotography of the prototype. Table III summarizes the main measurements on the LVR. The dynamic behavior of the LVR is depicted in Figure 7 where an input step signal is applied at a load current of $0.5 \mathrm{~mA}$. It can be seen that the LVR output voltage is stable, without any overshoot, and it presents a setup time of $16 \mu \mathrm{S}$.

The transient response of the LVR circuit also indicates a BIBO (Bounded Input - Bounded Output) system. Table IV shows a comparison of our work with previous reported regulators. ESR stands for Equivalent Series Resistance and indicates the presence of an external discrete capacitor at node output. 


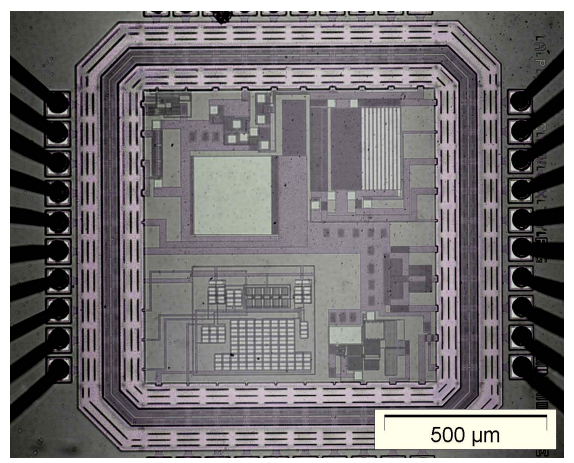

Figure 6-Microphotography of the chip.

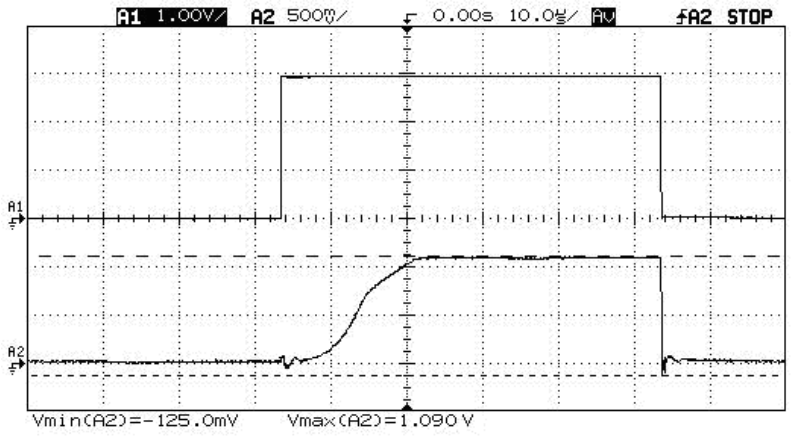

Figure 7- Step function response @ $\mathrm{I}_{\mathrm{L}}=0,5 \mathrm{~mA}$ and $\mathrm{T}=37^{\circ} \mathrm{C}$.

TABLE III

LVR MEASURED PARAMETERS

\begin{tabular}{|c|c|}
\hline Parameters & Measured \\
\hline $\mathrm{T}_{\mathrm{NOM}}\left[{ }^{0} \mathrm{C}\right]$ & 37 \\
\hline $\mathrm{V}_{\mathrm{NOM}}\left(\mathrm{V}_{\mathrm{IN}}\right)[\mathrm{V}]$ & 2.2 \\
\hline $\mathrm{V}_{\text {OUT }}[\mathrm{V}]$ & $1.073 @ \mathrm{I}_{\mathrm{L}}=0.5 \mathrm{~mA}$ \\
\hline $\mathrm{V}_{\mathrm{DROP}} @ \mathrm{~V}_{\mathrm{NOM}}=2.2 \mathrm{~V}[\mathrm{mV}]$ & 47 \\
\hline $\mathrm{I}_{\mathrm{L}}[\mathrm{mA}]$ & 0.5 \\
\hline $\mathrm{I}_{\mathrm{Q}}[\mu \mathrm{A}]$ & 35.7 \\
\hline $\mathrm{P}_{\mathrm{D}}[\mathrm{mW}]$ & 1.19 \\
\hline$\Delta \mathrm{V}_{\text {OUT }} / \Delta \mathrm{V}_{\mathrm{IN}} @ \mathrm{I}_{\mathrm{L}}=0.5 \mathrm{~mA}[\mathrm{mV} / \mathrm{V}]$ & 39 \\
\hline$\Delta \mathrm{V}_{\mathrm{OUT}} / \Delta \mathrm{I}_{\mathrm{L}} @ \mathrm{~V}_{\mathrm{IN}}=2.2 \mathrm{~V}[\mathrm{mV} / \mathrm{mA}]$ & 13 \\
\hline $\mathrm{PSRR} @ 10 \mathrm{MH} \mathrm{Z}_{\mathrm{Z}}[\mathrm{dB}]$ & $-38.1 @ \mathrm{I}_{\mathrm{L}}=0.5 \mathrm{~mA}$ \\
\hline $\mathrm{T}_{\mathrm{SET}} @ \mathrm{~V}_{\mathrm{NOM}}, 0.1 \%[\mu \mathrm{S}]$ & $16.6 @ \mathrm{I}_{\mathrm{L}}=0.5 \mathrm{~mA}$ \\
\hline
\end{tabular}

TABLE IV

COMPARISON WITH PREVIOUS REPORTED REGULATORS

\begin{tabular}{|c|c|c|c|c|}
\hline & $\begin{array}{c}\text { This } \\
\text { Work }\end{array}$ & {$[13]$} & {$[14]$} & {$[15]$} \\
\hline Technology $[\mu \mathrm{m}]$ & 0.35 & 0.18 & 0.35 & 0.35 \\
\hline $\mathrm{V}_{\text {OUT }}[\mathrm{V}]$ & 1 & 0.9 & 1 & 2.8 \\
\hline $\mathrm{I}_{\mathrm{L}} \max [\mathrm{mA}]$ & 0.5 & 50 & 100 & 50 \\
\hline $\mathrm{I}_{\mathrm{Q}}[\mu \mathrm{A}]$ & 35.7 & 1.2 & 100 & 65 \\
\hline$\Delta \mathrm{V}_{\text {OUT }} / \Delta \mathrm{V}_{\text {IN }}[\mathrm{mV} / \mathrm{V}]$ & 39 & 3.625 & 0,344 & 0.4 \\
\hline$\Delta \mathrm{V}_{\text {OUT }} / \Delta \mathrm{I}_{\mathrm{L}}[\mathrm{mV} / \mathrm{mA}]$ & 13 & 0.148 & 0.338 & 2.5 \\
\hline $\mathrm{PSRR}[\mathrm{dB}]$ & -38 & - & - & -57 \\
& $@ 10 \mathrm{MH}_{\mathrm{Z}}$ & & $-1 \mathrm{KH}_{\mathrm{Z}}$ \\
\hline $\mathrm{T}_{\mathrm{SET}}[\mu \mathrm{S}]$ & 16.6 & 4 & - & 15 \\
\hline $\mathrm{ESR}^{*}$ Required & $\mathrm{No}$ & Yes & No & No \\
\hline & & & &
\end{tabular}

\section{CONCLUSIONS}

This work presented a Linear Voltage Regulator for physiological monitoring systems that is activated by a RF link. The regulator was designed specifically for important conditions such as low power consumption, low silicon area and the absence external discrete components. The output voltage is regulated to a $1 \mathrm{~V}$ at maximum load current of $0.5 \mathrm{~mA}$ and the dissipated power is $1.2 \mathrm{~mW}$. The load regulation is $13 \mathrm{mV} / \mathrm{mA}$ and the line regulation is $39 \mathrm{mV} / \mathrm{V}$. The dynamic behavior shows an unconditionally stable response.

\section{ACKNOWLEDGMENT}

The authors acknowledge CAPES, CNPq and FAPEMIG.

\section{REFERENCES}

[1] M. Miyazaki, "The Future of e-Health - Wired or not Wired," Business Briefing: Hospital Engineering \& Facilities Management, 2005, pp1-5.

[2] J. Landt., "The History of RFID," Potentials, IEEE, Volume 24, Issue 4, Oct - Nov, 2005, Page(s): 8-11.

[3] G. A. Rincon-Mora and P. E. Allen, "Study and Design of Low DropOut Regulators," School of Electrical and Computer Engineering Georgia.

[4] G. A. Rincon-Mora and P. Allen, "A low-voltage, low quiescent current, low drop-out regulator,” IEEE J. Solid-State Circuits, vol. 33, pp 36-44, Jan 1998 .

[5] C. Simpson, "A User's Guide to Compensating Low-Dropout Regulators," Wescon/97, Conference Proceedings, 4-6 NOV. 1997 Page(s): 270-275.

[6] B. G. Song et all, "A $1.8 \mathrm{~V}$ Self-Biased Complementary Folded Cascode Amplifier,” ASICs, 1999. AP ASIC'99. The First IEEE Asia Pacific Conference on, 23-25 Aug. 1999 Page(s): 63-65.

[7] L. H. C. Ferreira and T. C. Pimenta, "A Week Inversion Composite MOS Transistor for Ultra-Low-Voltage and Ultra-Low-Power Applications," Proceedings of 13th International Conference Mixed Design Integrated Circuits Systems Gdynia, Jun. 2006.

[8] A. Becker-Gomes et all, A Low-Supply-Voltage CMOS Sub-Bandgap Reference, IEEE Transactions on Circuits and Systems II: Express Briefs, Vol. 55, no. 7, pp 609-613, July 2008.

[9] K. N. Leung and P. K. T. Mok, A sub-1-V 155-ppm/ $/{ }^{\circ} \mathrm{C}$ CMOS bandgap voltage reference without requiring low thereshold voltage device, IEEE Journal of Solid-State Circuits, Vol. 37, no. 4, April 2002.

[10] G. De Vita and G. Ianaccone, A sub-1-V $10-\mathrm{ppm} /{ }^{\circ} \mathrm{C}$ Nanopower Voltage Reference Generator, IEEE Journal of Solid-State Circuits, Vol. 42, no. 7, pp 1536-1542, July 2007.

[11] K. Dejhan et all, "A CMOS Voltage-Controlled Grounded Resistor Using a Single Power Supply," Communications and Information Technology, 2004. ISCIT, IEEE International Symposium on, Volume 1, 26-29 Oct. 2004 Page(s): 124-127 vol. 1.

[12] E. Rogers, "Stability Analysis of Low-Dropout Linear Regulators with a PMOS Pass Element," Texas Instruments Incorporated. Analog Applications Journal, Aug. 1999, Page(s): 10- 12.

[13] T. Y. Man, P. K. T. Mok, and M. Chan, "A High Slew-Rate Push-Pull Output Amplifier for Low-Quiescent Current Low-Dropout Regulators With Transient-Response Improvement," IEEE Trans. Circuits Syst. I, Volume. 54, no. 9, Sept. 2007, page(s): 755-759,.

[14] S. Lau, et. all, "A Low-Dropout Regulator for SoC with Q-Reduction," IEEE J. Solid-State Circuits, volume 42, May 2007, page(s): 658-664.

[15] R. J. Milliken, J. Silva-Martínez, and E. Sánchez-Sinencio, "Full OnChip CMOS Low-Dropout Voltage Regulator,' IEEE Trans.Circuit and System I, volume.54, Dec. 2007, page(s):1879-1890. 